\title{
A Validated Method for Pit Lake Water Sampling Using Aerial Drones and Sampling Devices
}

\author{
Devin Castendyk ${ }^{1} \cdot$ Jimmy Voorhis $^{1} \cdot$ Bradley Kucera $^{2}$
}

Received: 3 March 2019 / Accepted: 28 February 2020 / Published online: 17 March 2020

(c) The Author(s) 2020

\begin{abstract}
Pit lakes present significant safety risks for boat-based water sampling crews. The Matrice-HydraSleeve method improves the safety of water sampling in pit lakes by eliminating the need for a boat-based sampling crew. The method connects an off-the-shelf unmanned aircraft system, or drone (DJI, Matrice 600) to an off-the-shelf water sampling device (GeoInsight, HydraSleeve). It is capable of collecting $1.75 \mathrm{~L}$ water samples from up to $122 \mathrm{~m}$ deep and is simpler than previous drone water sampling methods. To validate the method, water samples were collected from similar depths in Dillon Reservoir, Colorado, USA using the Matrice-HydraSleeve method and traditional boat sampling methods using a Van Dorn water sample bottle. Concentrations of $\mathrm{Ca}, \mathrm{Na}, \mathrm{K}, \mathrm{HCO}_{3}, \mathrm{SO}_{4}, \mathrm{Cl}$, and $\mathrm{Zn}$ showed less than $20 \%$ relative percent difference, and concentrations of $\mathrm{Cd}$ were within \pm the detection limit, meaning variability between samples met the data quality objective for duplicate samples. The method was also used on two occasions to collect eight water samples from the $101 \mathrm{~m}$ deep pit lake at the Thompson Creek mine in Idaho, USA including a sample from $92 \mathrm{~m}$ deep. Calcium and sodium concentration profiles were nearly identical, indicating little change in water chemistry and providing confidence in the method. In situ profiles of temperature and electrical conductivity collected with a conductivity-temperature-depth probe (YSI, CastAway) suspended below the drone indicated the lake was meromictic during both sampling events. To date, the Matrice-HydraSleeve method has been used at 10 pit lakes in the USA to collect 81 samples. Use of this method at other pit lakes has the potential to improve safety while lowering sampling costs and increasing data acquisition, leading to better pit lake management.
\end{abstract}

Keywords UAS $\cdot$ UAV $\cdot$ Matrice $\cdot$ HydraSleeve $\cdot$ Monitoring $\cdot$ Thompson Creek Mine

\section{Introduction}

Globally, $70 \%$ of the properties owned by the six largest mining companies exist in water-stressed regions (Beck 2018), where open pit mining often results in the formation of pit lakes following mine closure (Castendyk and Eary 2009). Given the value of water in these regions, postclosure pit lake water quality is highly scrutinized by companies, regulators, and the public. Routine water sample collection at multiple depths in the pit lake water column informs site water management; results are used to calibrate predictive water quality models, inform closure planning and trade-off studies, design appropriate water treatment plants,

\footnotetext{
Devin Castendyk

Devin_Castendyk@golder.com

Golder Associates Inc., Lakewood, CO, USA

2 Thompson Creek Mining Company, Challis, ID, USA
}

and monitor treatment progress and efficiency. Such studies factor into financial assurance estimates used in closure planning, bond calculations, and stakeholder disclosures. Pit lake water sampling enables stakeholders to develop wellinformed closure plans and limit future liabilities. However, the benefits of pit lake characterization must be weighed against the risks of sample acquisition.

Some pit lakes expose boat-based water sampling personnel to lethal hazards, including work on water, work below highwalls, and handling hazardous liquids. Potential risks include drowning, hypothermia, skin contact with acutely toxic water, impact from falling rocks, impact from landslide debris, boat inundation or capsize by large waves generated by landslides, falls from pit walls, and asphyxiation from lake degassing, among others. The severity of each risk is magnified by the remoteness of most pit lakes, the potential lack of cellular and radio communications inside the pit, and possibly difficult access for emergency response crews once they arrive. These risks are not limited to pit lakes; in Oct 
2017, a contractor drowned after falling into a coal ash pond in Kentucky, USA (Rhoads 2017), underscoring the risk of working on or near water.

This paper discusses a water sampling method designed for pit lakes that improves safety by eliminating the need for humans to access the water surface. The method combines (a) a high-payload, unmanned aircraft system (UAS), also called an unmanned aerial vehicle (UAV), or more commonly, a drone; (see FAA (Federal Aviation Administration) 2019), and (b) a water sampling device that collects water from a discrete depth interval. In some cases, especially in difficult-to-access water bodies, the drone method may cost less than boat-based methods and require less mobilization time. As a result, the drone method has the potential to increase the frequency of sampling and data acquisition, leading to more efficient water management. The purpose of this paper is three-fold:

1) To introduce the Matrice-HydraSleeve method;

2) To demonstrate that the Matrice-HydraSleeve method provides data with the same quality as traditional boatbased water sampling methods; and

3) To present a case study where the Matrice-HydraSleeve method allowed a mining company to resume pit lake data collection by eliminating sampling risks to humans.

We begin with an overview of drone water sampling techniques in general, followed by a summary of published drone water sampling techniques that have been applied to pit lake environments. We then give a description of the Matrice-HydraSleeve method and describe its strengths and limitations. Next, we provide a side-by-side comparison of water samples collected from the Dillon Reservoir in Colorado, USA using the Matrice-HydraSleeve and boat-based methods. Finally, we provide a case study of the MatriceHydraSleeve method used on two occasions (Nov 2018 and June 2019) at the Thompson Creek Mine pit lake near Challis, Idaho, USA.

\section{Experience with Drone Water Sampling}

\section{Overview of Drone Water Sampling}

Drones are being used in a wide variety of research and industrial applications (Kelleher et al. 2018; ITRC (Interstate Technology and Regulatory Council) 2019). In broad terms, drone applications involve imagery (visible light and other wavelengths), geophysics (aerial magnetics, etc.), and direct sample collection including gases (D'Arcy et al. 2018) and water. The ITRC has recently prepared a guidance document that reviews various drone applications used in contaminated site characterization and provides case studies (ITRC 2019).
Apart from the pit lake sampling efforts described later in this paper, the authors are aware of seven combinations of drone and sampling devices that have been used for drone water sampling (Table 1), the earliest of which is attributed to sampling in Nebraska in 2013 (Ore et al. 2015). Reported sampling campaigns have focused on shallow water sampling over large spatial areas in wetlands (Ore et al. 2015; Schwarzbach et al. 2014), lakes (Cornell et al. 2016; Koparan et al. 2018; Terada et al. 2018), and nearshore ocean (AC 2019; Washburn et al. 2018). This body of work demonstrated that drone sampling can be used to collect surface water samples with a quality similar to those collected using boat-based sampling methods for less cost and more safely, especially when applied in remote locations.

Water sample chambers, called "HydraSleeves," are well suited for drone water sampling. HydraSleeves are a patented, no-purge, groundwater sampling device manufactured by the GeoInsight Company in Las Cruces, New Mexico, USA (www.hydrasleeve.com). The device consists of a cylindrical plastic bag with a narrow diameter, which is designed to be lowered down a groundwater well to a desired sample depth. When vertically lifted, the HydraSleeve collects water until the bag fills and then self-seals via a checkvalve near the top to prevent additional water from entering the bag, resulting in a water sample collected from a discrete water depth. Multiple studies demonstrate the efficacy of HydraSleeves for groundwater collection (e.g., Savoie and LeBlanc 2012). Although the HydraSleeve was designed for well water sampling, its ability to collect a sample from a target depth interval and its low weight make it ideal for deep water sampling using drones. Additionally, GeoInsight manufactures a wide mouth sample cone that attaches to the opening of the HydraSleeve and aids in rapidly filling the HydraSleeve from a water body. On Aug 12, 2019, the New Zealand based engineering company Pattle Delamore Partners used a HydraSleeve connected to a quad copter to collect nearshore seawater samples to assess beach water quality (AC 2019). On Oct 26, 2019, the Hawaii Volcano Observatory of the US Geological Survey used the MatriceHydraSleeve method to sample the Halemaumau Crater Lake on the Big Island of Hawaii (https://www.usgs.gov/ media/videos/sampling-water-halema-uma-u-k-lauea-volca no).

In a recent review of drone water sampling methods, Lally et al. (2019) conclude that current drone sampling has the potential to fulfil some aspects of physical, chemical, and biological sampling required to meet large-scale water sampling programs in a safer, efficient, and more cost-effective manner. However, they note that the principal limitations of existing systems include: (1) inconsistencies between water chemical parameters collected by drones and traditional methods, (2) the limited volume of water collected $(\leq 500 \mathrm{~mL})$, and (3) inconsistent sample retrieval 
rates. We add a fourth limitation to this: (4) the depth of sampling in existing methods has until now been restricted to $\leq 5 \mathrm{~m}$. These limitations restrict the ability of the methods presented in Table 1 to monitor deep, stratified water bodies such as mine pit lakes, where a total sample volume of 1.5-3.0 L of water may have to be collected from multiple depths to meet monitoring requirements. For example, in the USA, Nevada's Department of Environmental Protection (NDEP) requires pit lakes deeper than $7.6 \mathrm{~m}$ to be sampled at three depths: the shallow layer (i.e., epilimnion), the transitional layer (i.e., metalimnion), and the deep layer (i.e., hypolimnion) (Newman et al. 2018). None of the published methods listed in Table 1 except for the HydraSleeve have been demonstrated to be capable of sampling from depths greater than $5 \mathrm{~m}$ and, as such, would be unsuitable for regulatory compliance monitoring of deep pit lakes in Nevada.

\section{Drone Water Sampling in Pit Lakes}

The authors are aware of four drone sampling methods that have been applied in pit lakes, described below in chronological order. At the foundation of these methods is the Matrice 600 hexa-copter drone (Matrice), released in 2016 by the Chinese aerial drone manufacturer DJI. This drone, with a cost of $\approx \$ 5600$ USD (in 2019) and a payload capacity of $6 \mathrm{~kg}$, made it possible to collect larger volumes of water for an affordable price tag. The Matrice has subsequently been adopted in three of the four drone water sampling programs described below. We have named each method using the drone platform followed by the water sampling device.

\section{Quad Copter-Rectangular Bottle Method}

In July 2016, the aerial photography and videography company IRYS Pty Ltd in Western Australia became the first company to document pit-lake sampling with a drone (IRYS 2016). The company used two thin, rectangular, $500 \mathrm{~mL}$ water sample bottles mounted beneath a quad-copter drone to collect surface water samples from a pit lake in the abandoned Tallering Pit at the Mount Gibson Mine in Western Australia. This work removed the need for field technicians to be exposed to high risks posed by accessing pit lakes with unstable pit walls and geological units (MIRS (Dept of Mines, Industry Regulation and Safety) 2017). Video footage shows the drone landing on the surface of the pit lake using four floatation devices mounted below each rotor (IRYS 2016). In this position, the sample bottles were submerged a few centimeters below the water surface and filled with water. The drone returned to the staging area where analytical bottles were filled.

Notable limitations of the quad copter-rectangular bottle method are the inability to collect water samples at depth and to collect in situ profiles of physicochemical parameters, as well as the drone's exposure to the water surface and wave action. The authors could not find evidence of this technique being applied at other pit lakes, or a paper validating the method against standard lake sampling procedures.

\section{Matrice-Niskin Method}

In 2016, the engineering company Hatch Associates in Lakewood, Colorado, USA, in collaboration with the University of Colorado, Boulder, developed an attachment that allowed a Matrice to carry a 1.2 L Niskin water sample bottle (from the company General Oceanics). A full description of this method is provided in Castendyk et al. (2017). Briefly, the Niskin bottle was suspended by a tether below the drone. A metal messenger was connected to the tether and held by a messenger-release device on the belly of the drone. After a pilot navigated the Matrice to the desired sample location and lowered the Niskin bottle to a desired sample depth, a custom-built remote-control device released the messenger, which travelled the length of the tether and closed the Niskin. Depth data from a Micro-Diver pressure transducer (Van Essen Instruments) attached to the Niskin bottle were used to verify the sample depth to an accuracy of $\pm 10 \mathrm{~cm}$, at depths ranging to $100 \mathrm{~m}$.

Table 1 Studies of shallow-water drone sampling, unrelated to pit lakes

\begin{tabular}{llll}
\hline Reference & $\begin{array}{l}\text { Sample volume } \\
\mathrm{mL}\end{array}$ & $\begin{array}{l}\text { Sample depth } \\
\mathrm{m}\end{array}$ & Description of sampling device \\
\hline Schwarzbach et al. (2014) & 500 & 0 & 1.5-m-long tube with onboard pump \\
Ore et al. (2015) & 20 & $<1$ & 1-m-long tube with onboard pump \\
Cornell et al. (2016) & 50 & 0 & Falcon tube dipped below surface \\
Koparan et al. (2018) & 130 & $0.6-0.8$ & Thief-style, messenger-triggered bottle \\
Terada et al. (2018) & 250 & $<0.8$ & Sample tube with check-valve \\
Washburn et al. (2018) & 500 & 5 & Bottle closes autonomously at a specified pressure \\
AC (2019) & 1750 & $0-1$ & HydraSleeve \\
\hline
\end{tabular}


Prior to water sampling, Hatch suspended a YSI CastAway conductivity-temperature-depth (CTD) probe from the Matrice and measured in situ profiles of temperature, electrical conductivity, and water density (Castendyk et al. 2017). This $0.45 \mathrm{~kg}$ CTD measures parameters at five times a second during its decent and ascent through the water column to a maximum depth of $100 \mathrm{~m}$. These profiles define the upper and lower depth of individual water layers within the lake as well as the maximum depth of the pit lake for lakes shallower than $100 \mathrm{~m}$. In the field, CTD data are used to: (1) find the surface location above the deepest portion of the pit lake; (2) select appropriate sample depths; and (3) verify that samples are collected from the correct depth using ex situ specific conductance measurements on water samples. In situ profiles also provide a useful indication of the physical state of the lake, notably, the extent of vertical mixing during seasonal turnover events.

Between Oct 2016 and Aug 2017, Hatch used the Matrice-Niskin method to sample two pit lakes in Ontario, Canada and five pit lakes in Nevada, USA, collecting water from a maximum depth of $80 \mathrm{~m}, 800 \mathrm{~m}$ laterally from the pilot (Castendyk et al. 2018). A representative from the NDEP observed pit lake sampling using the Matrice-Niskin method in Aug 2017, and reported "the methodology is acceptable for regulatory purposes and allows for multiple samples to be collected while maintaining human and environmental safety" (Newman et al. 2018).

The Matrice-Niskin method has three limitations. First, between the empty Niskin bottle $(4 \mathrm{~kg})$, sample water $(1.2 \mathrm{~kg})$, and messenger $(0.5 \mathrm{~kg})$, the total weight of equipment suspended below the drone $(5.7 \mathrm{~kg})$ is near the limit of the recommended payload mass of the Matrice $(6 \mathrm{~kg})$. Therefore, the size of the water sample is limited by the weight of the other components of the payload. Assuming drone technology continues to improve, the maximum allowable payload mass is likely to increase in the future, allowing for heavier systems like the Matrice-Niskin method to collect additional water. Another limitation involves the need for two custom-built pieces of equipment, the messengerrelease device and the messenger-release remote-control, which adds to the system complexity and potential failure points. A final limitation, applicable to any sampling method that suspends a sampling device below a drone, results from current regulatory limits for the altitude of commercial drone operations. In the USA and Canada, the FAA and Transport Canada, respectively, limit the flight ceiling for commercial drone operations to $122 \mathrm{~m}$ (i.e., 400 feet) above the land surface. Given that the Niskin is suspended below the Matrice, this limits sampling to a maximum depth of $122 \mathrm{~m}$. Exemptions are available from both agencies.

\section{Matrice-HydraSleeve method}

The Matrice-HydraSleeve method is introduced here for the first time. Developed by Golder Associates in Lakewood, Colorado, the Matrice-HydraSleeve method replaces the Niskin bottle with a $2.0 \mathrm{~L}$ HydraSleeve, resulting in a simpler method with significantly less payload weight and no need for a custom-built messenger-release device or remote control (Fig. 1). The Matrice-HydraSleeve method uses a surface water collection cone at the mouth of the HydraSleeve (available from GeoInsight) and collects a large sample volume $(\approx 1.75 \mathrm{~L})$ (Fig. 2$)$. The HydraSleeve equipment (i.e., collection cone, sleeve, connection collar, and bottom weight) weighs $\approx 0.6 \mathrm{~kg}$, whereas the $100 \mathrm{~m}$ long tether line weighs $\approx 0.75 \mathrm{~kg}$. For a $1.75 \mathrm{~L}$ water sample, the total payload weight is $\approx 3.0 \mathrm{~kg}$, or half the payload weight limit of the Matrice. A video of the method can be found at http:// bit.ly/golder-drone-water.

The Matrice-HydraSleeve method uses the following procedure: (1) profile the water column with a CastAway CTD suspended below the Matrice; (2) select target sample depths based on CTD profiles; (3) affix the HydraSleeve to the Matrice and navigate to the desired sample point; (4) place the HydraSleeve sample cone on the water surface, hover the Matrice, and record the hovering altitude of the drone; (5) calculate the sampling altitude of the drone at the target sample depth by subtracting the target sample depth from the hovering altitude; (6) lower the drone to the sampling altitude; (7) pause for $\approx 30$ s per $25 \mathrm{~m}$ depth to allow time for the HydraSleeve to descend to the target sample depth and for the pressure transducer to register the "maximum depth" of the HydraSleeve; (8) raise the drone vertically in a continuous motion. During its ascent, the HydraSleeve fills with a $1.5 \mathrm{~m}$ long, $1.75 \mathrm{~L}$ column of water; (9) fill sample bottle from the HydraSleeve; and (10) process pressure transducer data to verify the actual sample depth.

Golder first demonstrated the Matrice-HydraSleeve method for Denver Water (the water utility for the Denver metropolitan area) at Dillon Reservoir, Colorado in Sep 2018 (Proctor 2018). Subsequently, between 27 Sep 2018 and 12 Nov 2019, Golder collected 81 water samples from eight pit lakes in Nevada, one pit lake in Montana (Montana Tunnels pit lake, see Castendyk et al. 2019), and one pit lake in Idaho where samples were collected down to a depth of $92 \mathrm{~m}$ (Thompson Creek Mine pit lake). Table 2 shows the location, date, and depth of each sample collected by Golder. Representatives from the US Bureau of Land Management (BLM) and the Montana Department of Environmental Quality (MDEQ) observed the method at the Montana Tunnels Mine Pit Lake on 23 Oct 2018, and accepted water samples for regulatory compliance monitoring (Williams et al. 2018). As discussed in Castendyk et al. (2019), this pit lake 
Fig. 1 The Matrice in flight with a full HydraSleeve over a Nevada pit lake in September 2018

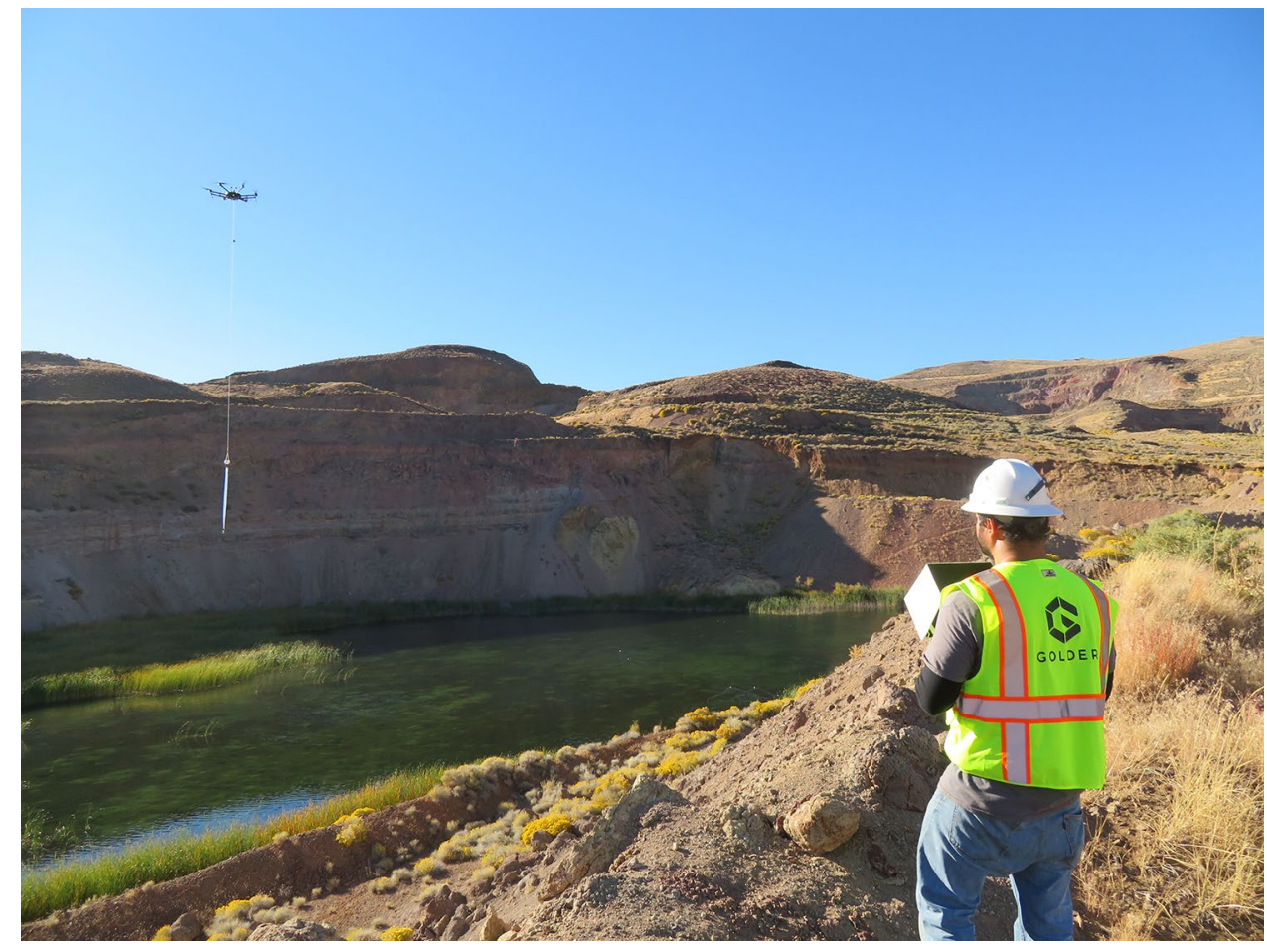

was inaccessible to any water sampling methods other than aerial sampling because of landslide debris, which blocked all access to the water surface.

Several factors limit the depth and operating conditions for the Matrice-HydraSleeve method, largely driven by regulations and operating conditions. Like the Matrice-Niskin method, samples collected by the Matrice-HydraSleeve method are currently limited to a depth of $122 \mathrm{~m}$ due to the flight ceiling for commercial drone operations in the USA and Canada. This is because sampling equipment is suspended below the drone at a length equal to the maximum sample depth. For example, to collect a sample from $122 \mathrm{~m}$, the HydraSleeve would be attached to the end of a $122 \mathrm{~m}$ long tether suspended below the drone, and the drone would need to fly to an altitude of $122 \mathrm{~m}$ to lift the HydraSleeve off the ground. Sampling deeper depths is possible provided the pilot receives a flight-ceiling waiver (in the USA and Canada). However, the authors have not yet had the opportunity to test the method on a pit lake deeper the $101 \mathrm{~m}$, and as such, the physical depth limitations of the method have not been studied or quantified. In the absence of a flight ceiling, we estimate that the method would be limited to a maximum depth of $\approx 460 \mathrm{~m}$, at which point the payload weight would equal the maximum payload weight of the Matrice (this estimate assumes a $460 \mathrm{~m}$ long tether weighing $3.5 \mathrm{~kg}$, a $1.75 \mathrm{~L}$ sample weighing $1.75 \mathrm{~kg}$, and HydraSleeve equipment weighing $0.6 \mathrm{~kg}$. This does not consider the weight of water in the wet sample line or a margin of safety). Another physical limit is the CastAway CTD used to measure in situ profiles, which has a maximum depth range of $100 \mathrm{~m}$.

Fig. 2 A full, 1.5-m-long HydraSleeve after drone sampling 
Table 2 Pit lake sample depths using the Matrice-HydraSleeve method from 2018 to 2019

\begin{tabular}{|c|c|c|c|c|c|c|c|c|c|c|}
\hline \multirow{2}{*}{$\begin{array}{l}\text { Pit Lake name } \\
\text { Thompson Creek }\end{array}$} & \multirow{2}{*}{$\begin{array}{l}\text { Location } \\
\text { Idaho }\end{array}$} & \multirow{2}{*}{$\begin{array}{l}\text { Sample date } \\
13 \text { Nov. } 2018\end{array}$} & \multicolumn{2}{|c|}{$\begin{array}{l}\text { Shallow } \\
\text { layer (m) }\end{array}$} & \multicolumn{4}{|c|}{ Transitional boundary (m) } & \multicolumn{2}{|c|}{$\begin{array}{l}\text { Bottom } \\
\text { layer } \\
(\mathrm{m})\end{array}$} \\
\hline & & & 3 & 8 & 15 & 17 & 36 & 40 & 55 & 83 \\
\hline & & 6 June 2019 & 6 & & 23 & & 43 & & 92 & \\
\hline Montana Tunnels & Montana & 23 Oct. 2018 & 0 & & 28 & & & & 56 & \\
\hline \multirow[t]{3}{*}{ South Mega } & Nevada & 25 June 2019 & 2 & & 8 & & & & 62 & \\
\hline & & 4 Sep. 2019 & 1 & & 7 & & & & 60 & \\
\hline & & 12 Nov. 2019 & 5 & & 20 & & & & 55 & \\
\hline \multirow[t]{3}{*}{ North Mega } & Nevada & 25 June 2019 & 0 & & 6 & & & & 11 & \\
\hline & & 4 Sep. 2019 & 2 & & 6 & & & & 12 & \\
\hline & & 12 Nov. 2019 & 2 & & 7 & & & & 12 & \\
\hline \multirow[t]{4}{*}{ Ashcraft } & Nevada & 27 Sep. 2018 & 5 & & 15 & & & & 25 & \\
\hline & & 19 June 2019 & 5 & & 18 & & & & 24 & \\
\hline & & 5 Sep. 2019 & 5 & & 18 & & & & 24 & \\
\hline & & 16 Oct. 2019 & 5 & & 16 & & & & 23 & \\
\hline \multirow[t]{4}{*}{ Northwest } & Nevada & 27 Sep. 2018 & 4 & & 8 & & & & 13 & \\
\hline & & 19 June 2019 & 1 & & 6 & & & & 14 & \\
\hline & & 5 Sep. 2019 & 0 & & 5 & & & & 13 & \\
\hline & & 16 Oct. 2019 & 1 & & 5 & & & & 12 & \\
\hline \multirow[t]{4}{*}{ South } & Nevada & 27 Sep. 2018 & 3 & & 9 & & & & 15 & \\
\hline & & 19 June 2019 & 1 & & 5 & & & & 14 & \\
\hline & & 5 Sep. 2019 & 1 & & 6 & & & & 13 & \\
\hline & & 16 Oct. 2019 & 2 & & 6 & & & & 14 & \\
\hline \multirow[t]{4}{*}{ Main* } & Nevada & 27 Sep. 2018 & 0 & & - & & & & - & \\
\hline & & 19 June 2019 & 1 & & - & & & & - & \\
\hline & & 5 Sep. 2019 & 0 & & - & & & & - & \\
\hline & & 16 Oct. 2019 & 1 & & - & & & & - & \\
\hline \multirow[t]{4}{*}{ West* } & Nevada & 27 Sep. 2018 & 1 & & - & & & & - & \\
\hline & & 19 June 2019 & 1 & & - & & & & - & \\
\hline & & 5 Sep. 2019 & 1 & & - & & & & - & \\
\hline & & 16 Oct. 2019 & 1 & & - & & & & - & \\
\hline \multirow[t]{4}{*}{ North* } & Nevada & 27 Sep. 2018 & 3 & & - & & & & - & \\
\hline & & 19 June 2019 & 2 & & - & & & & - & \\
\hline & & 5 Sep. 2019 & 2 & & - & & & & - & \\
\hline & & 16 Oct. 2019 & 2 & & - & & & & - & \\
\hline
\end{tabular}

*Pit lake had a maximum depth $<7.6 \mathrm{~m}$ and exhibited uniform temperature and specific conductance profiles at the time of sampling
Experience has shown that the method is only useful under low-wind conditions with a smooth water surface, no low-lying clouds, and no rain. High winds push the drone, which requires extra battery power for stabilization. Additionally, winds can cause the HydraSleeve to swing below the drone, and lead to challenges with landing the equipment. Due to high winds, Golder's drone was damaged during one sampling event, which prevented further sample collection until the drone was repaired. Wind speed complications are best mitigated by beginning sampling events at sunrise, when wind speeds are generally lowest in most settings.
A final limitation of the Matrice-HydraSleeve method is the potential for errors associated with sampling a specific depth within $\pm 2 \mathrm{~m}$. These errors could be caused by vertical and horizontal drift. Vertical drift can occur when the Matrice makes adjustment to maintain altitude, the sample line stretches, or there are accuracy errors with the pressure transducer. Horizontal drift occurs while the sampler is sinking through the water column. Ideally, a sample device would sink vertically (i.e., at a $90^{\circ}$ angle from the water surface). However, the sample device can sink at an angle $<90^{\circ}$, making the sample depth shallower than the length of the tether. This can reduce the precision associated with collecting replicate samples from the same depth. The deeper the 
targeted depth, the more likely horizontal drift will influence the actual sample depth. The weight added to the bottom of the HydraSleeve reduces the horizontal drift; however, the authors have not yet quantified the optimal weight needed to minimize horizontal drift. Both vertical and horizontal drift also occur in boat sampling, and the large surface area of a boat makes it more susceptible to being pushed horizontally by wind and waves during sampling. By comparison, drones use an on-board global positioning system (GPS) to maintain a constant horizontal position, which can minimize errors associated with horizontal drift.

\section{Matrice-Bailer Method}

The hydrological services consultancy MWES (2019), based in East Perth, Western Australia has posted a video online showing a Matrice 600 connected to a bailer (used in wells) sampling an undisclosed pit lake. This method is simple and efficient, but like the quad copter-rectangular bottle method, it can only collect a surface water sample. No other information is available on this method or the results.

\section{Validation of the Matrice-HydraSleeve Method}

\section{Objective and Site Location}

To validate the drone sampling method, Golder compared the Matrice-HydraSleeve method to standard boat-based lake sampling using a Van Dorn water sampler at Dillon Reservoir in Colorado, USA on 10 July 2019. Dillon Reservoir, located in the Front Range of the Rocky Mountains at an elevation of $2748 \mathrm{~m}, 93 \mathrm{~km}$ west of Denver, is part of the water supply system for the Denver metropolitan area, and is surrounded by the towns of Dillon, Silverthorne, and Frisco. Drainage from historic mines in the region contributes $\mathrm{Zn}$ and $\mathrm{Cd}$ to the reservoir's major tributaries, the Blue and Snake Rivers, and these analytes are routinely monitored by the owner, Denver Water. The sample location for this study was situated $\approx 250 \mathrm{~m}$ from a peninsula on the northeast shore of the reservoir at latitude: $39.6154570^{\circ}$, longitude: $-106.046023^{\circ}$, and was expected to have a depth of $50 \mathrm{~m}$. Golder established a drone operations area on the peninsula with an unobstructed view of the sample location.

\section{Method for Matrice-HydraSleeve Sampling}

While one team member (the pilot) was setting up the drone (DJI, Matrice 600 Pro), a second team member (the spotter) calibrated a handheld multi-parameter probe (Hanna 991301) to measure ex situ temperature, electrical conductivity, and pH. By comparison, the CTD (YSI, CastAway) was factory-calibrated in early 2018, and otherwise cleaned after each use in 2018 and 2019. Following the methods described previously, the sampling team gathered in situ profiles of temperature, specific conductance, and density using the CTD, assessed target sample depths based on chemical boundaries defined by the specific conductance profile, and then used the drone to collect three water samples from target depths of 4,18 , and $40 \mathrm{~m}$ (see below).

Prior to the first water sampling flight, a pressure transducer (VanEssen, Micro-Diver) was attached to the sample cone. During each flight, the transducer recorded the deepest point the HydraSleeve intake reached. The spotter prepared a HydraSleeve and placed it $\approx 5 \mathrm{~m}$ away from the drone before take-off to avoid dust blowing into the sample cone from the drone's rotor wash. The pilot followed the procedure described above to retrieve the sample from the target depths.

The spotter filled two pre-washed $500 \mathrm{~mL}$ sample bottles from the HydraSleeve: one for analysis of major cations and trace metals and the second for major anions. The cation bottle contained concentrated nitric acid for sample preservation. The spotter poured the remaining sample water into a beaker and measured ex situ temperature and specific conductance using the multiparameter probe.

After collecting three samples, the pilot removed the pressure transducer from the sample cone and downloaded the sample depths. These data provided the "actual depth" from which the HydraSleeve began its ascent through the water column with an accuracy of $\pm 10 \mathrm{~cm}$ up to $100 \mathrm{~m}$ depth: 3.1, 17.1 , and $38.4 \mathrm{~m}$. Because the HydraSleeve is a $1.5 \mathrm{~m}$ long, vertically-oriented water sampler, it collected an integrated sample from $1.5 \mathrm{~m}$ above the actual depth.

\section{Method for Boat-Van Dorn Sampling}

The Van Dorn bottle is a horizontally-oriented water sampler widely used in lake water sampling. It consists of a $20 \mathrm{~cm}$ diameter tube with rubber caps covering both ends, internally connected by a strong elastic cord. Much like a Niskin bottle, the caps are attached to a trigger in an "open" position, and a messenger is used to trigger the bottle to close after it reaches a target depth. The Golder personnel tied the Van Dorn to a $2 \mathrm{~mm}$ thick, static (i.e., minimal-stretch), nylon line marked at 1 and $10 \mathrm{~m}$ increments, for a total length of $60 \mathrm{~m}$, and connected the same pressure transducer to the Van Dorn. The target depth for the Boat-Van Dorn method was set to $1 \mathrm{~m}$ above the actual depth of the HydraSleeve $(2.1 \mathrm{~m}, 16.1 \mathrm{~m}$, and $37.4 \mathrm{~m})$ to collect samples as close as possible to the HydraSleeve depths measured by the pressure transducer.

The sampling team boarded a boat, navigated to the sampling location, and used the Van Dorn sampler to retrieve three water samples. The boat drifted during sampling and 
was repositioned using a handheld GPS prior to collection of the next sample. The Golder personnel set the Van Dorn in an open position and lowered it to the target sample depth by counting the marked increments on the sample line. After holding the sampler in position for 50 seconds, a messenger was dropped down the sample line, which closed the Van Dorn. The sampling team pulled the Van Dorn to the surface and followed the same water sample collection procedures described above to fill sample bottles and measure field parameters. After the last sample was collected, the pressure transducer was removed from the Van Dorn sampler and the team downloaded the sample depth data.

Both sets of water samples were put on ice and shipped to TestAmerica in Savannah, Georgia for analysis. The anion sample was analysed for alkalinity and bicarbonate alkalinity by titration (Standard Method 2320B-2001), and chloride and sulfate using ion chromatography (EPA Method 300.0). The cation sample was analysed for the major cations: total $\mathrm{Ca}$, total $\mathrm{K}$, and total $\mathrm{Na}$, and the trace metals, total $\mathrm{Cd}$, total $\mathrm{Mn}$, and total $\mathrm{Zn}$ using inductively-coupled plasma mass spectrometry (ICP-MS; EPA Method 6020A).

\section{Evaluation of Duplicate Sample Collection}

Precision was used to evaluate the quality of the drone water sample relative to the boat water sample. Precision is an indicator of whether analyzing one constituent of the same sample multiple times results in the same value. The data precision was evaluated using the relative percent difference (RPD), as defined by the US Environmental Protection Agency (EPA (US Environmental Protection Agency) (1994)):

$R P D=\frac{|S-D|}{(S+D) / 2} \times 100$

where $S$ is the measured concentration in the first sample (i.e., drone sample) and $D$ is the measured concentration in the second sample (i.e., boat sample). In this analysis, the method detection limit is referred to as the contract required detection limit (CRDL). For analytes with concentrations $>5 \times$ CRDL, duplicate samples with RPD of less than $\pm 20 \%$ meet the typical data quality objective for duplicates. Therefore, the variability in the data produced by the different methods would be acceptable for duplicate samples, and we would conclude that the drone method produced data of equal quality as the boat method. For analytes with concentrations $<5 \times$ CRDL, $S$ must be within \pm the CRDL of $D$ to meet data quality objectives.

\section{Results of Lake Structure and Target Depth Selection}

Figure 3 shows profiles of in situ temperature and specific conductance in Dillon Reservoir measured by the CTD suspended below the drone, plus ex situ values measured by a multi-parameter probe. As indicated by the profiles, on 10 July, Dillon Reservoir exhibited a layer of relatively uniform temperature and specific conductance between 0 and $5 \mathrm{~m}$ (interpreted as the epilimnion), a transitional layer with decreasing temperature and increasing specific conductance between 5 and $35 \mathrm{~m}$, and a layer with relatively uniform temperature and specific conductance between 35 and $46.5 \mathrm{~m}$ (interpreted as the hypolimnion). Using these profiles, Golder targeted depths of 4, 18, and $40 \mathrm{~m}$ in order to collect a representative sample from each water layer. Figure 3 also compares the in situ water temperatures recorded by the CTD to the ex situ temperature using the hand-held multi-parameter probe. For most samples, ex situ temperatures were $\approx 2{ }^{\circ} \mathrm{C}$ higher than in situ temperatures. This shift impacted the HydraSleeve samples and the Van Dorn samples similarly, suggesting that the temperature increase was caused by warming during sample retrieval. This is consistent with the findings of a review of drone water sampling by Lally et al. (2019), who noted that water samples collected by drones had a different temperature than in situ water samples. The same study recommended the use of in situ multi-parameter probes, such as a CTD, to obtain accurate temperatures.

In contrast, ex situ specific conductance values generally agreed with each other and with in situ CTD values at the same depth (Fig. 3 and Table 3). This consistency indicates that drone samples were collected from the intended target depth, and that the drone and boat samples had a similar concentration of total dissolved solids. The ex situ measurements from the drone sample were the same as the in situ values in the shallow sample, $20 \mu \mathrm{S} / \mathrm{cm}$ higher for the middle sample, and $10 \mu \mathrm{S} / \mathrm{cm}$ higher for the deep sample.

\section{Results of Sample Depth Comparisons}

Pressure transducer data allowed the Golder personnel to verify whether the drone collected water from the intended depth. The difference between the target and actual depths for the Matrice-HydraSleeve method was $-0.9,-0.9$, and $-1.6 \mathrm{~m}$ for the shallow, middle, and deep sample, respectively (Table 3 ). The actual depth was slightly shallower than the target depth during each flight, and the difference between these values increased with depth. These findings are consistent with Golder's experience (see below). For lakes with homogeneous water layers $>2 \mathrm{~m}$ in thickness, such as the epilimnion and hypolimnion in Dillon Reservoir, this error is insignificant (Fig. 3). However, for very thin 


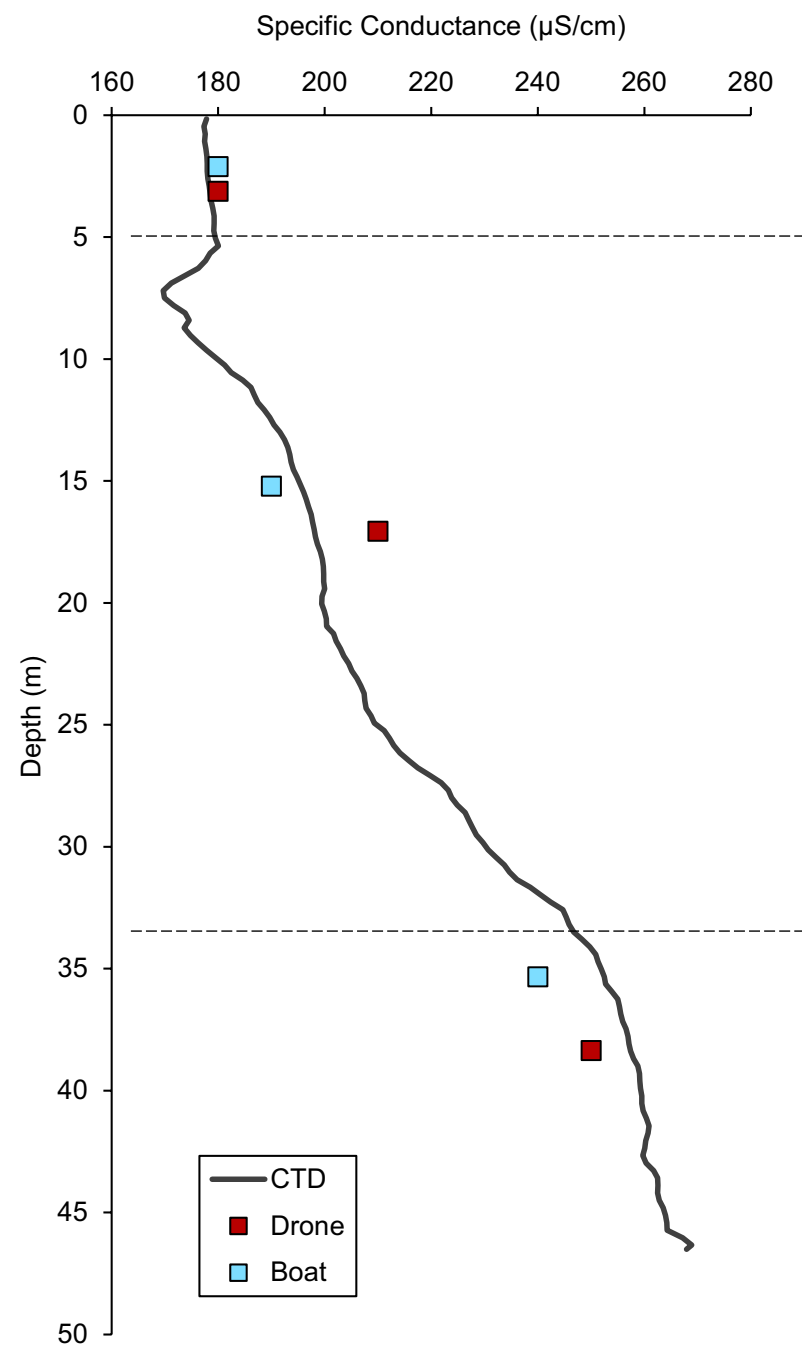

Fig. 3 Profiles of specific conductance (left) and temperature (right) measured in Dillon Reservoir, Colorado, on 10 July 2019 using in situ (CTD sonde) and ex situ (multiparameter probe for drone and boat

layers $(<2 \mathrm{~m})$, it may be difficult to collect a sample from just the target depth using the Matrice-HydraSleeve method (i.e., the sample device has a greater length than the layer thickness).

Pressure transducer data showed the maximum depth reached by both the HydraSleeve and the Van Dorn bottle. The actual depths were different by $1.0,1.9$, and $3.0 \mathrm{~m}$ for the shallow, middle, and deep samples, respectively (Table 3). With the boat method, Golder intentionally targeted $1 \mathrm{~m}$ shallower than the actual depth for the drone samples to capture water from the median depth of the HydraSleeve. As such, the actual differences between methods were $0.0,0.9$, and $2.0 \mathrm{~m}$, respectively. The Van Dorn depth was consistently shallower than the HydraSleeve depth. The Van Dorn is wider and less streamlined

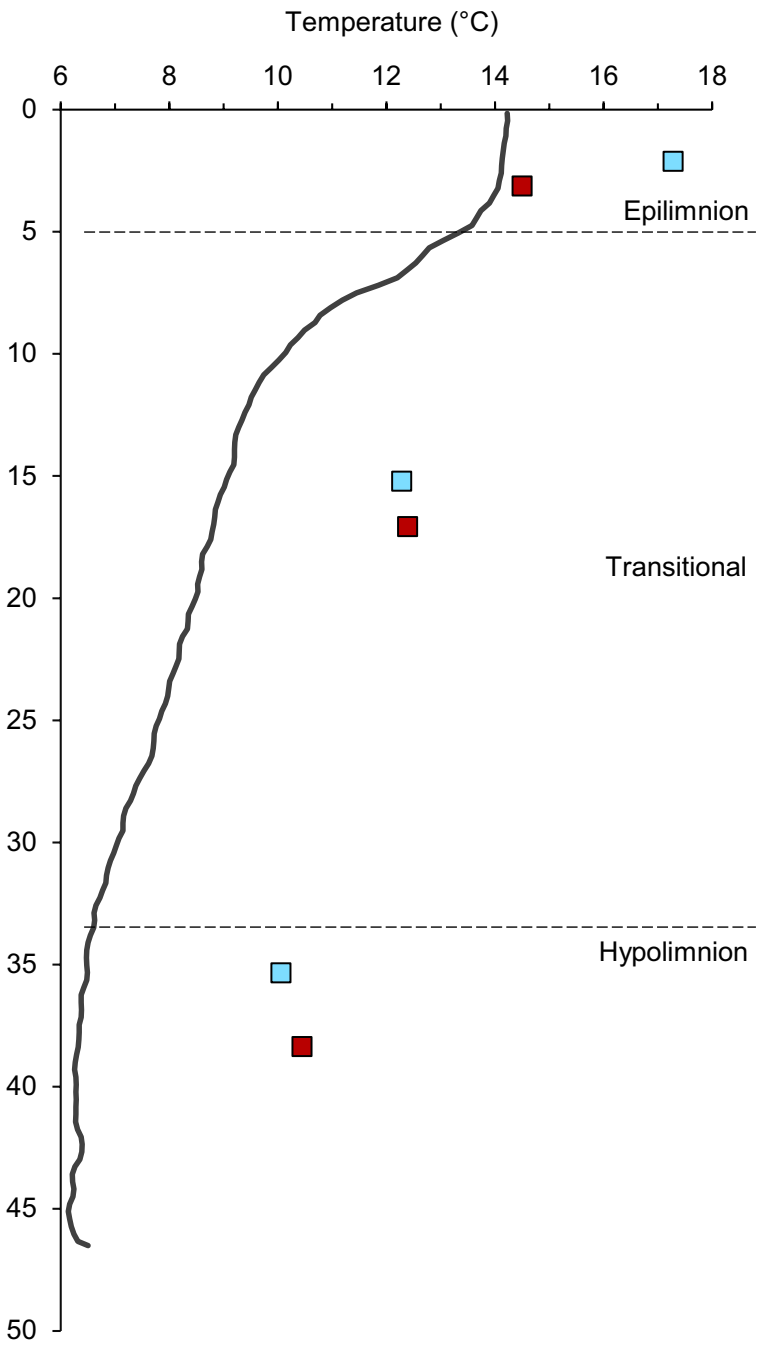

samples) methods. Interpreted layer boundaries are indicated by horizontal dashed lines

than the HydraSleeve, and was observed to drift horizontally during its descent through the water. Consequently, the sample line was not perpendicular to the water surface, and the Van Dorn was located at shallower depths in the water column than the markings on the sample line indicated. This error was compounded by the drift of the boat during sample collection. We suspect this is a common source of depth error when using a Van Dorn. Unlike the HydraSleeve, the Van Dorn did not have a weight attached. However, the difference between intended sample depths was $\leq 2.0 \mathrm{~m}$. For samples collected from homogeneous layers in Dillon Reservoir, this error should cause little difference in water chemistry; however, this depth error may have contributed to small differences in water chemistry between the samples from the transitional layer. 


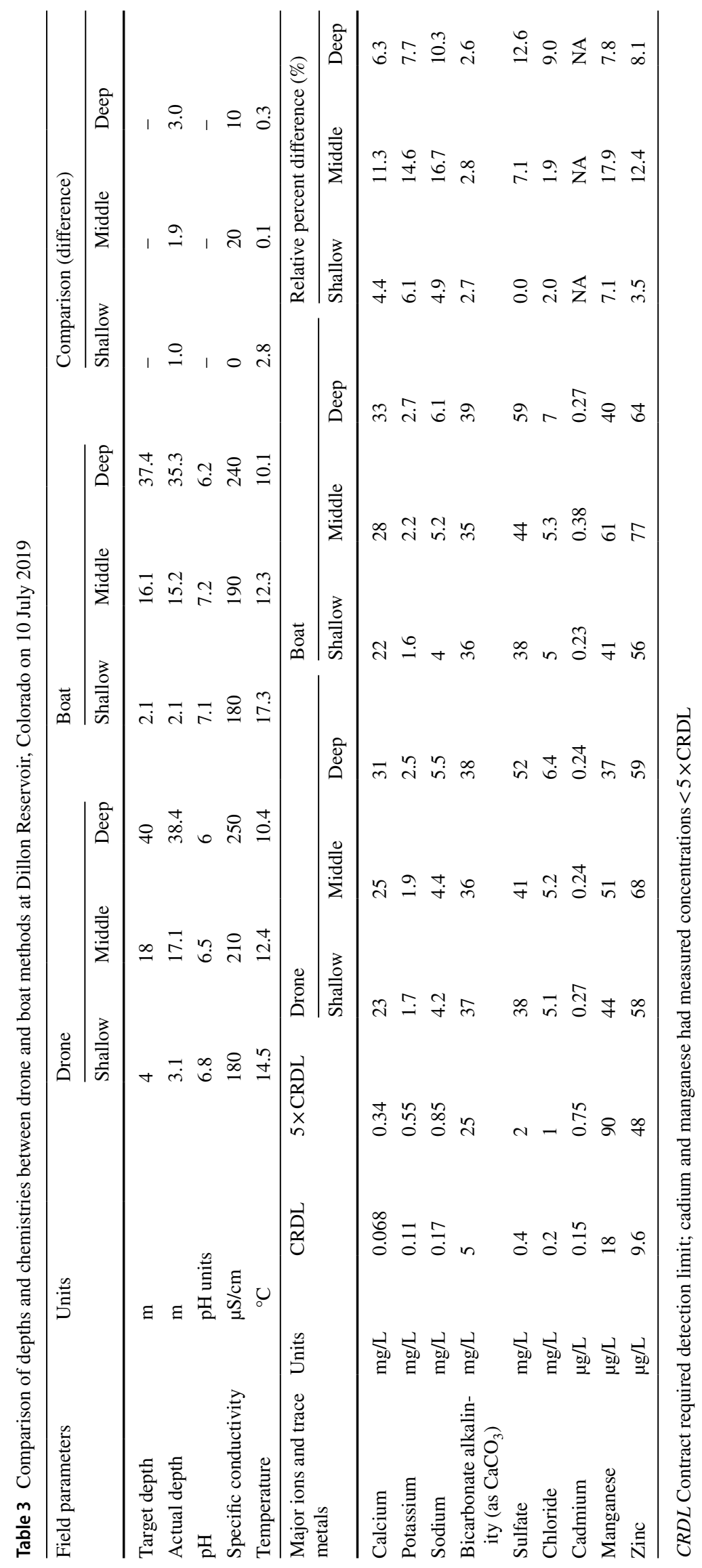




\section{Results of Chemistry Comparison and Analysis}

Table 3 compares chemistry results from both methods and the RPD between analyses obtained from drone and boat samples. Except for $\mathrm{Cd}$ and $\mathrm{Mn}$, concentrations of each analyte exceeded $5 \times \mathrm{CRDL}$, and the RPD of the analytical results was less than $\pm 20 \%$. For Cd, sample concentrations were within \pm the CRDL for all samples. As such, the drone sampling method obtained chemistry data equivalent to those collected using traditional boat sampling methods under EPA guidelines.

The lowest RPD values were observed for the surface samples, and the largest differences were found for the middle samples. We attribute the latter to the known depth error of $\approx 2 \mathrm{~m}$ between samples, and the gradational increase in chemistry as a function of depth within the transitional layer (Fig. 3). For the middle samples, observed differences in sample chemistry reflect a change in the chemistry of the water column over a relatively small depth interval. These differences reflect the precision of both methods to collect a sample at the exact same depth, rather than the accuracy of either sampling method.

\section{Case Study from the Thompson Creek Mine Pit Lake, Idaho}

\section{Site Background}

The Thompson Creek pit lake is a $101 \mathrm{~m}$ deep water body located at the Thompson Creek molybdenum mine near Challis, Idaho, USA (latitude $44.315208^{\circ}$, longitude: $-114.551634^{\circ}$ ). Active open-pit mining ceased in Dec 2014 and the site went into a care and maintenance phase. During operations, pumps were used to control groundwater infiltration and to dewater the mine pit. When the pumps were turned off, a temporary pit lake developed.

The Thompson Creek Mining Company (TCMC), a subsidiary of Centerra Gold, planned to monitor the rate of change in pit water quality during care and maintenance to prepare for potential water treatment options in the event of restart or mine closure. However, landslides from pit walls into the pit lake frequently occurred, raising safety concerns about accessing the pit lake for boat-based sampling and other purposes. The most significant landslide took place in Dec 2016 and produced a large wave that resulted in substantial damage to equipment. This event exacerbated already heightened safety concerns about personnel working in boats on the pit lake, especially given that the first boat-based pit sampling had occurred less than a month prior to the landslide. No repeat boat-based sampling was attempted or has been planned since.
Table 4 Comparison of sample depths from Thompson Creek Pit Lake, Idaho, USA

\begin{tabular}{lccll}
\hline Date & Target depth & Actual depth & $\begin{array}{l}\text { Absolute } \\
\text { difference }\end{array}$ & $\begin{array}{l}\text { Sample } \\
\text { pair differ- } \\
\text { ence }\end{array}$ \\
& & & $\mathrm{m}$ & $\mathrm{m}$ \\
\hline 13 Nov 2018 & 0 & 2.8 & 2.8 & - \\
& 10 & 8.4 & 1.6 & - \\
& 17 & 15.4 & 1.6 & - \\
& 20 & 17.4 & 2.6 & - \\
& 40 & 35.8 & 4.2 & - \\
& 40 & 40.2 & 0.2 & - \\
6 June 2019 & 60 & 54.5 & 5.5 & - \\
(paired & 30 & 83.3 & 6.7 & - \\
samples) & 20 & 6.5 & 3.5 & 2.1 \\
& & 4.4 & 4.4 & \\
& & 25.0 & 5.0 & 4.8 \\
& 40 & 20.2 & 0.2 & \\
& & 40.3 & 0.3 & 5.0 \\
& 95 & 45.2 & 5.2 & \\
& & 91.7 & 3.3 & 0.1 \\
& & 91.6 & 3.4 & \\
\hline
\end{tabular}

\section{Matrice-HydraSleeve Sampling}

Golder initially sampled the Thompson Creek pit lake on 13 Nov 2018 using the Matrice-HydraSleeve method. This event included in situ profiling of temperature and specific conductance to a depth of $92 \mathrm{~m}$, and collecting eight $1.75 \mathrm{~L}$ HydraSleeve samples from depths of 3, 8, 15, 17, 36, 40, 55 , and $83 \mathrm{~m}$, respectively (Table 4). Samples were analysed by Energy Laboratories in Billings, Montana for total and dissolved concentrations of major cations and trace elements. Results from that event were originally presented in Castendyk et al. (2019) and are reinterpreted here based on new data.

After reviewing the data from Nov 2018, TCMC decided to repeat sampling in the spring of 2019 to assess the impact of fall and spring turnover events on vertical mixing within the water column, and to collect additional water for anion and nutrient analyses. The additional analytes required Golder to collect two 1.75 L HydraSleeve samples from the same target depth to provide the requisite volume for a complete suite of analyses. On 6 June 2019, Golder profiled the pit lake to a depth of $101 \mathrm{~m}$ with the CTD and obtained paired samples from median depths $6,23,43$, and $92 \mathrm{~m}$, respectively (Table 4). To the best of our knowledge, the $92 \mathrm{~m}$ sample is the deepest water sample collected to date using any aerial drone sampling method, in any environment.

Select results are discussed below to highlight the utility of the Matrice-HydraSleeve sampling approach. Given 


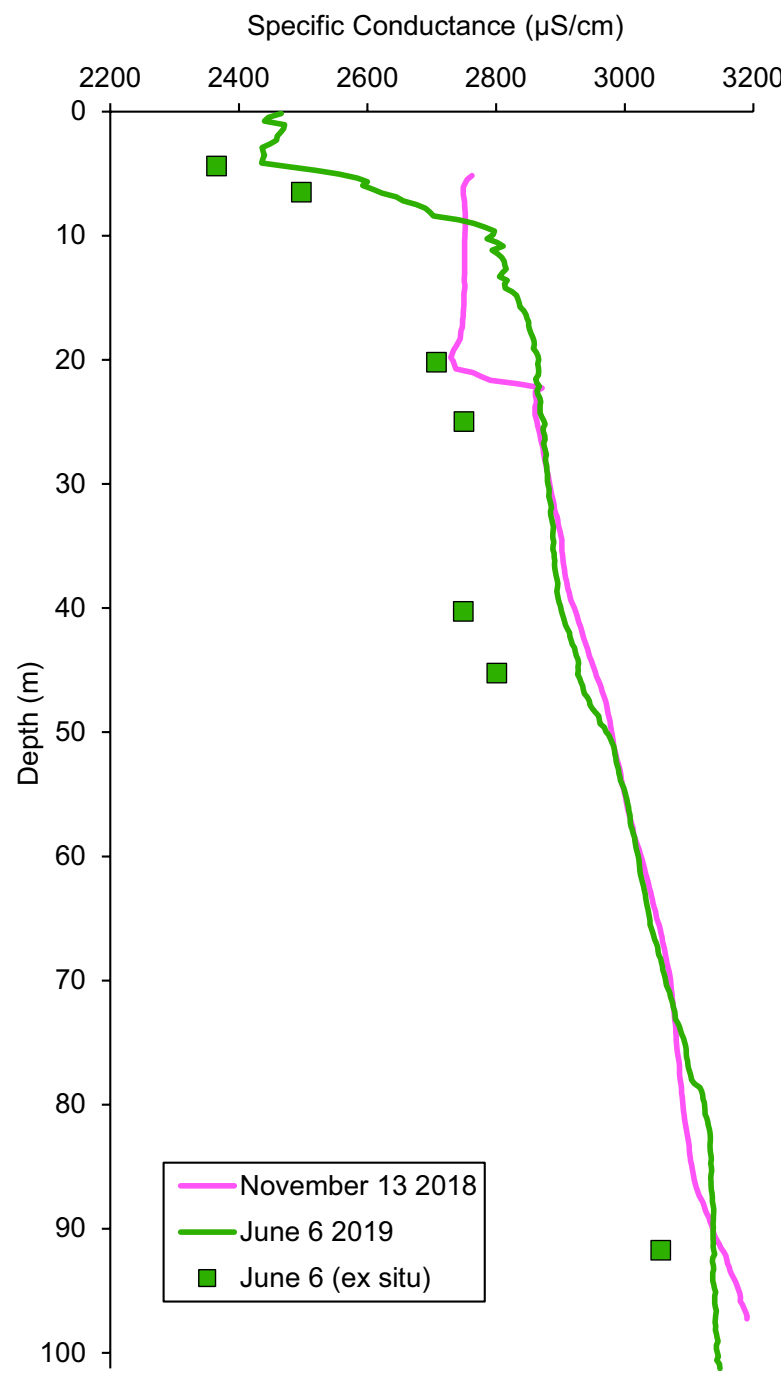

Fig. 4 Profiles of in situ specific conductance (left) and temperature (right) measured in the Thompson Creek Pit Lake in Idaho on 13 Nov 2018 and 6 June 2019. November 2018 profiles were lowered by $5 \mathrm{~m}$

health and safety risks associated with the landslides, these could not have been obtained using boat-based methods, and TCMC's knowledge of the lake would be limited to the Dec 2016 observations.

\section{Physical Limnology}

Profiles of in situ temperature and specific conductance measured on 13 Nov 2018 and 6 June 2019 are shown in Fig. 4. Because profiles were measured with respect to the water surface, the 2018 profiles were adjusted down $5 \mathrm{~m}$ to account for the rise in lake level reported by TCMC.

The Thompson Creek pit lake showed thermal stratification on 6 June 2019, with a thin epilimnion located between 0 and $3 \mathrm{~m}$, a transitional thermocline boundary

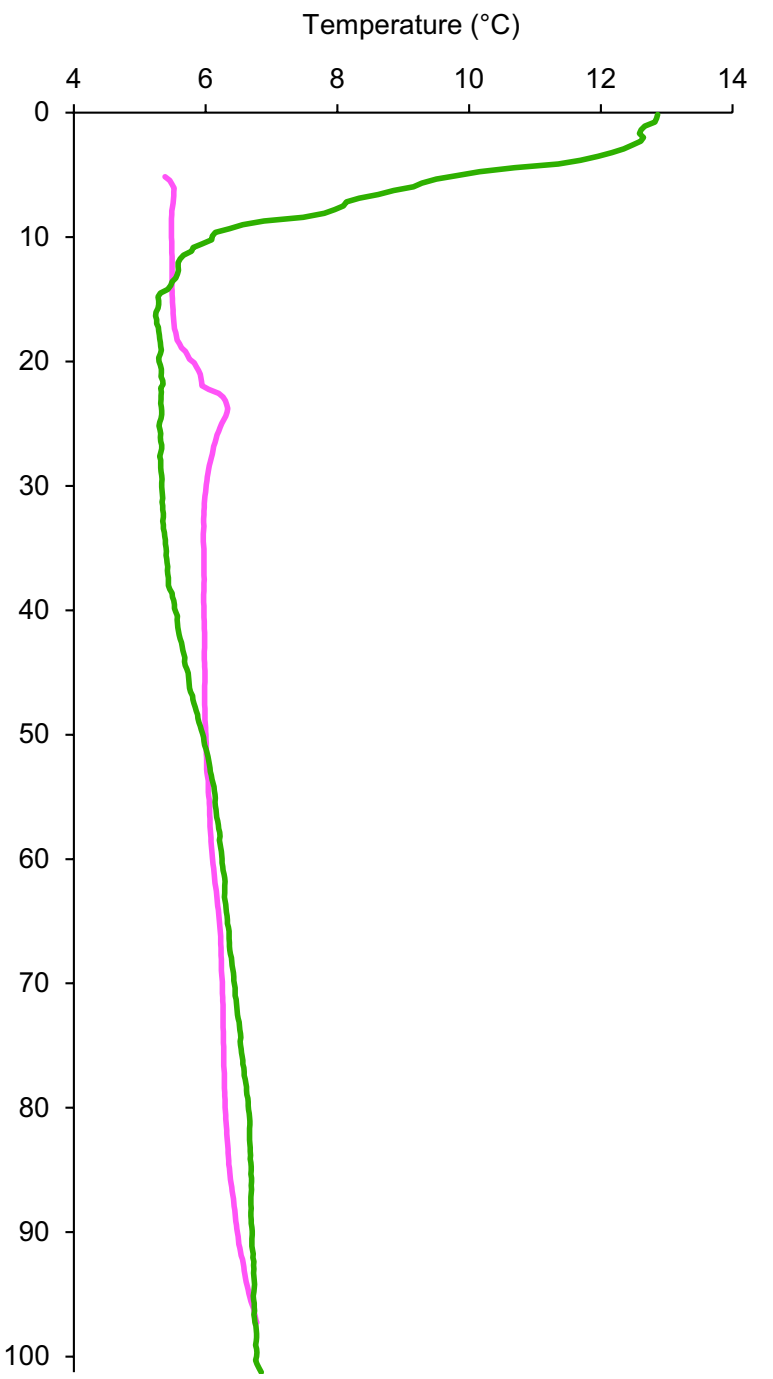

to account for an observed increase in water level between Nov 2018 and June 2019

layer between 3 and $10 \mathrm{~m}$, and a hypolimnion between 10 and $50 \mathrm{~m}$ (Fig. 4). Profiles of specific conductance showed the same stratification. Differences in temperature, specific conductance, and density profiles (not shown) between the Nov 2018 and June 2019 profiles illustrate that the upper $50 \mathrm{~m}$ of the water column circulated at least once between these dates, during fall 2018 or spring 2019, or during both turnover events.

Similarities in temperature, specific conductance, and density below $\approx 50 \mathrm{~m}$ depth, suggest the pit lake did not circulate below this depth during either turnover event. If this observation represents long-term behavior of the lake, the Thompson Creek pit lake would be characterized as a meromictic pit lake, which fully circulates above $50 \mathrm{~m}$ and is permanently stratified below $50 \mathrm{~m}$. The deep, isolated water layer is called a monimolimnion, and typically exhibits 
anoxic, reducing conditions. Meromictic conditions could provide unique opportunities for water management, such as metal sequestration through engineered sulfide precipitation in the monimolimnion.

We are aware of only one other meromictic pit lake currently existing in the United States: the Humboldt tailings disposal facility, an iron ore pit lake in Champion, Michigan (Nutini 2018). The Berkeley pit lake in Butte, Montana previously exhibited meromictic behaviour from 1986 until 2013, when a large landslide, coupled with the disposal of high-density sludge from the water treatment plant, triggered whole lake circulation. That lake is now holomictic, meaning it fully circulates on an annual basis (Castendyk et al. 2018; Griffin et al. 2018).

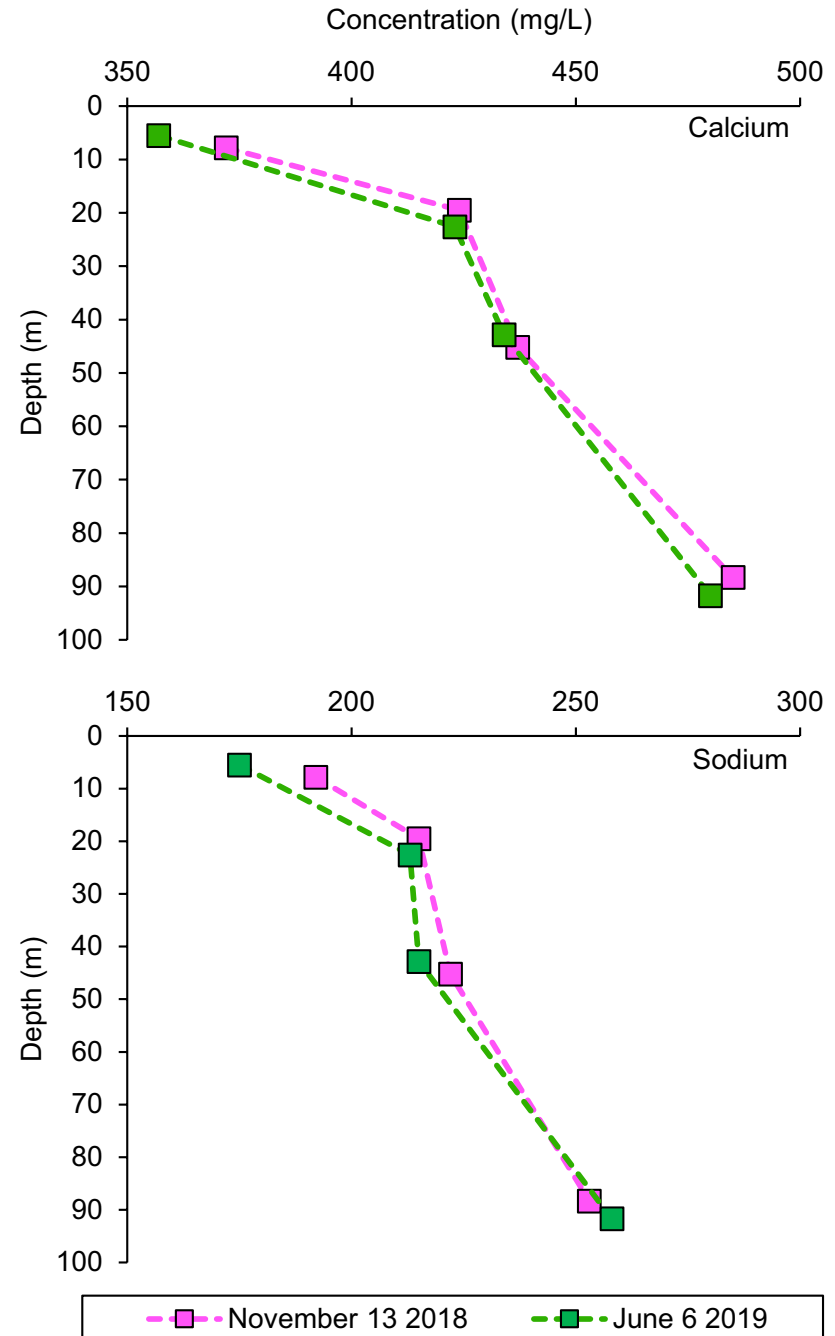

Fig. 5 Profiles of total calcium and sodium measured in Thompson Creek Pit Lake in Idaho on 13 Nov 2018 and 6 June 2019

\section{Sample Depth Precision}

The Matrice-HydraSleeve method collected water samples from the intended target sample depths with an acceptable degree of accuracy (Table 4). For the eight samples collected in Nov 2018, the difference between the target sample depths and actual sample depths ranged from 0.2 to $6.7 \mathrm{~m}$, with a general increase as a function of depth. For the four paired samples collected on 6 June 2019, the absolute difference ranged from 0.2 to $5.5 \mathrm{~m}$. In both cases, the maximum difference between the target and actual sample depths was considerably less than the thickness of the layer targeted for sampling (Fig. 4); thus, the drone sampling fulfilled the sampling objectives.

Differences between the actual depths of samples within a paired sample set ranged from 0.1 to $5.0 \mathrm{~m}$. This highlights the difficulty in collecting samples from an exact water depth with high precision using drone methods, potentially due to the length of the HydraSleeve $(152 \mathrm{~cm})$, horizontal drift of the HydraSleeve while passing through the water column, stretch in the sample line, and the accuracy of the altimeter on the drone $( \pm 0.5 \mathrm{~m})$. However, based on experience at Dillon Reservoir, the precision associated with drone sampling appears to be comparable to boat-based methods, especially considering the differences in actual and target depths due to boat drift (Table 3).

\section{Water Chemistry Results}

Figure 5 shows the $\mathrm{Ca}$ and $\mathrm{Na}$ concentration profiles measured in the Thompson Creek pit lake on 13 Nov 2018 and 6 June 2019. The similarity between these profiles demonstrates that the Matrice-HydraSleeve method provides reproducible results. In general, samples from the surface of the lake are dilute due to rainfall, while samples collected from the central depths of the lake are similar due to vertical mixing, which occurs above $50 \mathrm{~m}$ during fall or spring turnover events. Samples from the bottom of the lake are concentrated, as these are from an isolated "monimolimnion layer." Surface samples obtained in June 2019 were slightly more dilute than surface samples collected in Nov 2018 most likely due to water added to the lake between sampling events, which caused the lake level to rise.

\section{Discussions and Conclusions}

The Matrice-HydraSleeve method has a unique advantage in pit lakes where human sampling crews are subject to high safety risks using boat-based methods or where lake access does not otherwise exist. In our experience, both the cost of drone sampling and the time required for equipment mobilization are less than boat-based methods. As of Nov 
2019, we have used the method at ten pit lakes in the USA, and have collected 81 water samples from depths between the surface and $92 \mathrm{~m}$ deep. According to EPA guidelines, the method has an equivalent precision to boat-based methods for collecting water from a target sample depth. It can also collect in situ profiles of temperature and electrical conductivity from $\leq 100 \mathrm{~m}$ using a lightweight CTD. The method has been observed by federal and state regulators in the USA, and has been accepted for regulatory compliance monitoring in one state (Montana). Adopting this technology may result in more frequent pit lake water sampling, a better understanding of pit lake processes, and better overall management of these systems during operations, closure, and post-closure periods.

In the USA and Canada, the method is suitable for pit lakes $\leq 122 \mathrm{~m}$ deep, due to the regulatory altitude ceiling for commercial drone operations. In both countries, pilots can apply for a waiver for a higher flight ceiling, which could enable deeper sampling, possibly as deep as $460 \mathrm{~m}$.

There are several limitations to the Matrice-HydraSleeve method. The equipment cannot be used in moderate-to-high winds, rain, or low clouds. To minimize the risk of high winds, flights are generally performed in the morning. As noted in a previous review of drone water sampling methods (Lally et al. 2019), parameters measured ex situ using the Matice-HydraSleeve method also show a warmer temperature than in situ measurements, plus higher concentrations of dissolved oxygen than expected. This error is due to temperature changes and aeration that occurs during sample retrieval and when draining water from the HydraSleeve. However, the 20-min flight time limits the use of multiparameter probes (e.g., YSI EXO sondes) capable of measuring additional in situ parameters (e.g., $\mathrm{pH}$, dissolved oxygen) as these sensors typically require at least $2 \mathrm{~min}$ to stabilize at each depth. Furthermore, unlike the Matrice-Niskin method (Castendyk et al. 2016), the Matrice-HydraSleeve method does not presently have a quick-release option to jettison the payload in the event of an equipment snag, which places the drone at risk.

We recommend both regulatory and technological advancements to overcome these limitations. Regulatory approvals for flight-ceiling waiver applications could facilitate deeper sampling in the USA and Canada. Alternatively, a reel mechanism could be developed to lower and raise the HydraSleeve independent of the drone's altitude, thus minimizing the length of the equipment suspended below the drone. This could enable deeper sampling without the need for a waiver. A quick-release mechanism could be added, allowing the payload to be jettisoned in the event of a snag. Finally, a drone capable of landing on and taking off from the water surface could be developed. Theoretically, such a drone could be powered down during profiling or sampling of a very deep pit lake, thereby conserving battery power.
We expect several benefits and opportunities will arise from improvements in drone technology and regulations in the future. Competition between drone manufacturing companies will continue to lower the cost of equipment; other drones are now available that have deployed HydraSleeves (AC 2019). As drones continue to become lighter and more powerful, both flight durations and maximum payload weights will increase. This may allow drones to deploy larger multiparameter probes that can function below $100 \mathrm{~m}$ deep and can measure a broad range of in situ parameters. "Beyond-visual line-of-site" drone flights, currently requiring a waiver, could allow the MatriceHydraSleeve method to collect water samples at hard to see locations around a mine site, such as streams and distant pit lakes.

Such improvements could allow mining companies to reduce mobilization expenses by commissioning multiple drone-related studies while a drone and pilot are on site. Current drone-camera technology already enables pilots to create three-dimensional models of pit walls using "structure-from-motion" analysis (i.e., photogrammetry) that allows for geotechnical assessments of pit wall stability. Pilots could also suspend air monitoring equipment from drones to measure the flux of gases (e.g., hydrogen sulfide) from the pit lake surface. Other geophysical (e.g., magnetic and electrical resistivity) and imagery (e.g., thermal and multispectral) technologies are currently available for drones which could aid in mine closure planning and assessment. As such, we envision that future pilots will be equipped with a "tool box" containing a variety of samplers, cameras, and sensors that can be exchanged, allowing for a wide range of data to be collected from pit lakes and the surrounding mine site during a single visit.

Acknowledgements The authors thank the organizers of the 11th International Conference on Acid Rock Drainage (ICARD) in Pretoria, South Africa for the opportunity to expand our original conference paper. We also thank members of Golder's drone program, Brian Straight, Greg Lehn, and Matt Somogyi, for their contributions to this effort. We thank Bryce Hill at Montana Tech in Butte, Montana, Pierre Filiatreault at BBA in Sudbury, Ontario, and Americo Pino at Hatch Associates in Mississauga, Ontario, for their comments on earlier versions of this manuscript. We are extremely grateful to Brandon Ransom and Cathy Proctor at Denver Water for providing us access to Dillon Reservoir, transport to our study location, and for reporting on our work. We also thank Centerra Gold and the Thompson Creek Mining Company for permission to publish site data. Lastly, we thank the editorial staff and reviewers of this journal for their constructive feedback, which greatly improved this paper.

Open Access This article is licensed under a Creative Commons Attribution 4.0 International License, which permits use, sharing, adaptation, distribution and reproduction in any medium or format, as long as you give appropriate credit to the original author(s) and the source, provide a link to the Creative Commons licence, and indicate if changes were made. The images or other third party material in this article are included in the article's Creative Commons licence, unless indicated 
otherwise in a credit line to the material. If material is not included in the article's Creative Commons licence and your intended use is not permitted by statutory regulation or exceeds the permitted use, you will need to obtain permission directly from the copyright holder. To view a copy of this licence, visit http://creativecommons.org/licenses/by/4.0/.

\section{References}

AC (2019) Drone swoops into aid Safeswim water sampling. Our Auckland, an online publication of Auckland City Council (AC). https ://ourauckland.aucklandcouncil.govt.nz/articles/news/2019/05/ drone-swoops-in-to-aid-safeswim-water-sampling/. Accessed 11 Aug 2019

Beck C (2018) Keynote presentation. In: Annual Meeting, Society of mining, metallurgy, and exploration. Minneapolis

Castendyk D, Eary LE (eds) (2009) Mine pit lakes; characteristics, predictive modelling, and sustainability. Society of Mining, Metallurgy and Exploration, Littleton

Castendyk D, Straight B, Filiatreault P, Thibeault S, Cameron L (2017) Aerial drones used to sample pit lake water quality reduce costs and improve safety. Min Eng 69(7):20-28

Castendyk D, Hill B, Filiatreault P, Straight B, Alangari A, Cote P, Leishman W (2018) Experiences with autonomous sampling of pit lakes in North America using drone aircraft and drone boats. In: Wolkersdoffer C, Sartz L, Weber A, Burgess J, Tremblay G (eds) Proceedings of 11th International Conference on acid rock drainage (ICARD) and International Mine Water Association (IMWA) annual conference, vol 2, pp 1036-1041

Castendyk DN, Straight BJ, Voorhis JC, Somogyi MK, Jepson WE, Kucera BL (2019) Using aerial drones to select sample depths in pit lakes. In: Proceedings of Mine Closure Conferenc4, Perth, Australia. https://papers.acg.uwa.edu.au/p/1915_89_Castendyk/. Accessed 8 Mar 2020

Cornell D, Herman M, Ontiveros F (2016) Use of a UAV for water sampling to assist remote sensing of bacterial flora in freshwater environments. Undergraduate External Publications. Paper 17. http://fisherpub.sjfc.edu/undergraduate_ext_pub/17. Accessed 8 Mar 2020

D’Arcy F, Stix J, de Moor JM, Rüdiger J, Diaz JA, Alan A, Corrales E (2018) Drones swoop into measure gas belched from volcanoes. Eos 99:54. https://doi.org/10.1029/2018EO102329

EPA (US Environmental Protection Agency) (1994) Laboratory data validation functional guidelines for evaluating inorganics analyses. United State Environmental Protection Agency, Office of Solid Waste and Emergency Response, Publication 9240.1-26, EPA540/R-94/083

FAA (Federal Aviation Administration) (2019) Unmanned aircraft system. US Dept of Transportation. www.faa.gov/uas/. Accessed 6 Aug 2019

Griffin J, Williams D, Gammons C, Thompson M, Capoccia S (2018) Field trip to the Berkeley Pit: lessons learned from developing a pit lake in a porphyry copper deposit. In: Presented at 2018 Mine design, operations and closure Conference, Fairmont Hot Springs, Montana

IRYS (2016) Tallering peak, mid-west western Australia. YouTube video by IRYS Pty Ltd, July 12, 2016. https://www.youtube.com/ watch?v=rx4nmuieLDM. Accessed 11 Aug 2019

ITRC (Interstate Technology and Regulatory Council) (2019) Chapter 6: remote sensing. In: implementing advanced site characterization tools. Washington, DC. https://asct-1.itrcweb.org/6-remot e-sensing/. Accessed 8 Mar 2020
Kelleher C, Scholz CA, Condon L, Reardon M (2018) Drones in geoscience research: the sky is the only limit. Eos. https://doi. org/10.1029/2018EO092269

Koparan C, Koc A, Privette C, Sawyer C, Sharp J (2018) Evaluation of a UAV-Assisted autonomous water sampling. Water 10(5):655

Lally HT, O'Conner IO, Jensen OP, Graham CT (2019) Can drones be used to conduct water sampling in aquatic environments? A review. Sci Total Environ 670:569-575

MIRS (Dept of Mines, Industry Regulation and Safety) (2017). 2017 Awards for Excellence. Govt of Western Australia. http://www. dmp.wa.gov.au/Documents/Environment/2017_Awards_for_Excel lence_Booklet.pdf. Accessed 11 Aug 2019

MWES (2019) Drone water sampling, YouTube, June 28, 2019. https ://www.youtube.com/watch?v=mU84wYhDoTQ. Accessed 13 Aug 2019

Newman CP, Castendyk D, Straight B, Filiatreault P, Pino A (2018) Remote water-quality sampling of Nevada pit lakes using unmanned aircraft systems. Geol Soc Am. https://doi.org/10.1130/ abs/2018rm-313820

Nutini J (2018) Humboldt mill mine permit application amended request-request for additional information, eagle mine LLC Mine Permit MP 10 2010. Michigan Dept of Environmental Quality, Lansing. https://www.michigan.gov/documents/deq/2018-0312_Humboldt_Mill_Amendement_Response_to_Review_Condi tion_F4_617655_7.pdf. Accessed 10 Aug 2019

Ore JP, Elbaum S, Burgin A, Detweiler C (2015) Autonomous aerial water sampling. J Field Robot 32(8):1095-1113. https://doi. org/10.1002/rob.21591

Proctor C (2018) Water sampling takes flight at Dillon. Tap, an online publication of Denver Water, Oct 20, 2018. https://denverwate rtap.org/2018/10/20/water-sampling-takes-flight-at-dillon/. Accessed 10 Aug 2019

Rhoads C (2017) Kentucky worker's death highlights need for stricter safeguards at coal ash sites. Rhoads and Roads Injury Lawyers. https://www.rhoadsandrhoads.com/blog/kentucky-death-coal-ashpond/. Accessed 13 Aug 2019

Savoie JG, LeBlanc DR (2012) Comparison of no-purge and pumped sampling methods for monitoring concentrations of ordnancerelated compounds in groundwater, Camp Edwards, Massachusetts Military Reservation, Cape Cod, Massachusetts, 2009-2010. USGS Scientific Investigations Report 2012-5084. http://pubs. usgs.gov/sir/2012/5084. Accessed 12 Aug 2019

Schwarzbach M, Laiacker M, Mulero-Pázmány M, Kondak K (2014) Remote water sampling using flying robots. In: 2014 International Conference on unmanned aircraft systems (ICUAS), https://doi. org/10.1109/icuas.2014.6842240

Terada A, Morita Y, Hashimoto T, Mori T, Ohb T, Yagauch M, Kand W (2018) Water sampling using a drone at Yugama crater lake, Kusatsu-Shirane volcano, Japan. Planets Space 70(64). https:// link.springer.com/article/10.1186/s40623-018-0835-3. Accessed 8 Ma 2020

Washburn L, Romero E, Salazar D, Valdez-Shulz A, Welch Z, IglesiasRodriguez D (2018) Water sampling from aerial drones for water quality research in coastal and inland waters (2018) Ocean Science Meeting. Association for the Sciences of Limnology and Oceanography, Portland, Oregon

Williams D, Haight S, Jepson W, Smith G, Walsh D, Mohrmann J, Danesi D, Bell C (2018) Surface management inspection, Montana Tunnels Pit Lake, Jefferson City. US Bureau of Land Management, Butte, p 3809 